\title{
Developing Iraqi EFL School Students' Performance in Creative Writing Skills Through Focus Strategy
}

\author{
Sabeeha Hamza Dehham \\ Department of English, Faculty of Basic Education, Babylon University, Hilla City, Iraq \\ Email address: \\ sabeehadehham66@gmail.com

\section{To cite this article:} \\ Sabeeha Hamza Dehham. Developing Iraqi EFL School Students' Performance in Creative Writing Skills Through Focus Strategy. \\ International Journal of Language and Linguistics. Vol. 8, No. 4, 2020, pp. 128-134. doi: 10.11648/j.ij11.20200804.12
}

Received: January 6, 2020; Accepted: January 17, 2020; Published: June 20, 2020

\begin{abstract}
This study aims to investigate the effect of creative writing instruction on Focus Strategy. Creative writing is a very complicated process in which several different knowledge and skills work together simultaneously. The aim of the present study is to investigate empirically the effect of using focus strategy on creative writing skill \& developing on Iraqi EFL pupils '. Focus contains features such as generate new ideas, new ideas, realizing, alternatives and creativity. The present study is limited to the fifth-grade female students in the preparatory schools in Swerah City for the academic year 2018-2019. The sample of the study includes 32students as the experimental group and 32 as the control group. Then, it is ensured that the two groups are equal through a statistical analysis of a number of variables such as age, parent's education, and achievement scores in English in the end of first course examination. The researcher had planned performance assessments to be used as pre-test and post-test tests. For the analysis of the data obtained, a T-test formula is used for two separate samples. The results showed the superiority of the experimental group students in the performance test to the control group students.
\end{abstract}

Keywords: Creative Writing, EFL Preparatory School Students, Focus Strategy

\section{Introduction}

\subsection{Statement of the Problem}

The invention of writing the most important stages of human civilization and the transformation of the most dangerous effect in his life and the quality of the first moves that gave him described humanity through the communication achieved with other assists on the one hand and with the temporal dimension and historical processors and grandchildren on the other hand. [1]

Despite the importance of writing in human life, but it is noted that a large number of students at different stages suffer from apparent weakness, and it is assumed that students at the end of high school should be able to talk on any subject in line with their lives, needs or feelings and this means simply ready to write in most of the creative and functional topics. [2]

Writing is one of the productive skills which sometime seems difficult to acquire to the learners. There are many approaches to teach writing. Creative writing is one approach of teaching writing which has become more familiar in recent era, so writing plays a significant role in the academic Programs and future professional lives of students. [1]

Coombe [3] argues that writing is an essential component to academic success and it is a main part of any type of assessment besides its importance in an intensive English program, community, college, university and bound program by which many post-secondary programs require a writing sample before admission.

Mills [4] states that writing was a very late development in human history. The visual field of the written word (writing has to be seen, spatially mapped) differs fundamentally from sound sensations. We can only read print as individuals, while we hear collectively as an audience. Voice is produced by and resonates with, the body, it 'vanishes as soon as it is uttered', while writing 'separates the word from the living present, where alone spoken words can exist.

However, writing as speech, writing about speech, adds vital qualities to a text, and we might even claim that creative writing, developing as it has done from an oral tradition, not only reduces the separation between writing and voice but thrives on their proximity. If speech 'vanishes', creative writing keeps alive the traces of its vanishing. [4] 
Richard and Renandya [5] state that writing is an active skill which requires production more than recognition, so L2 writers have to note the higher level skills of planning and organizing and lower level skills of spelling, punctuation, word choice, and so on. The learners are asked to master the skill not only in gathering ideas and organizing them, but also in expressing those ideas in a readable text. So, the messages can be communicated successfully.

The role of creative writing is in increasing and deepening the use of word associations, elevating listening comprehension, and prompting writing skills can create an excellent learning environment [6].

Olson believes that if teachers want to help their students negotiate a cognitive task with confidence and competence, they need to think carefully about what to teach when they teach writing. For both cognitive and affective reasons, teachers need to expose students to a variety of domains or modes of writing, enable them to practice writing different types of topics and provide them with the declarative, procedural, and conditional knowledge of author's craft to move from conception to completion. [7]

Creative writing has a key role to play for students as practitioners in linking a fuller more internalized understanding of the linguistic composition of texts with a fuller understanding of how the parts are actively made to create the resonances of whole texts. [8]

In an ever more globalized world of concentrated wealth and major conflicts of class, interest texts reveal and conceal more than ever and learning to see through (in both senses of the phrase) the language of a variety of types of texts is a key 21 st-century competency. And such a focus allows for the fuller study of media and multimodal texts. [9]

Hewings et al. [8] also argue that the learning of English (including in many different contexts where English is learned as an additional language) can be significantly enhanced by a textual focus, whether that text is a single line at less advanced levels or a complete novel or complex political speech or multimodal advertisement or long narrative poem. [8]

The problem of this study is that Iraqi EFL preparatory school students face many difficulties when they manifest their creative writing performance. This is due to lack of suitable teaching techniques used by teachers to teach creative writing. This is not supported by a number of Iraqi studies that have, in one way or another, this study is the first that treatment creative writing in Iraq.

Creative writing is achieved by the students by proposing methods and exciting methods that raise their creative tendencies and develop creative writing skills. Therefore, the researcher employed the focus strategy which is one of the serious creative thinking in education, because it works directly on the development of the abilities creative in students and process the necessary skills in the diversity, and because it organizes information and ideas in ways that are unconventional in accordance with the mechanism in which the mind of the human mind and know the strength of the impact in lateral thinking of students and so it simulates the abilities of students mental. Thus, the researcher tries to know the effect of the focus strategy on developing and enhancing the skill of creative writing in teaching English language for the fifth-grade preparatory students.

This study deals with the focus strategy as one of the important strategies in the creative thinking or serious creativity by Eduard De Bono who develops an instrument of thinking system that receptive for learning that allows to individuals to practice the creativity and enable them to generate creativity thinking called serious creativity under name lateral thinking. [10]

Focus strategy which is the starting point for any creative thinking aims to generative new ideas and creative writing is the fledgling creative thinking. Thinking leads to improve writing, increase the imaginary, therefore, practicing on thinking skills leads to creativity in writing. [10]

\subsection{Aim of the Study}

The present study aims at investigating the effect of Focus Strategy in Developing of Iraqi EFL Preparatory School Students Skills in Creative Writing.

\subsection{Hypotheses}

The study aims at answering the following questions:

1. Is there a statistical difference between the students' mean scores of performance of the experimental group which is taught writing performance by means of the proposed technique and that of the control group which is taught writing according to the recommended method of teaching?

2. Does the use of focus technique help students write creatively?

\subsection{Limits of the Study}

The present study is limited to the writing skill which is a productive skill in addition to the following points:

1. Iraqi EFL $5^{\text {th }}$ preparatory students.

2. The academic year 2018-2019.

3. Focus technique.

4. The materials of the text book "English for Iraq"

5. The population will be presented by a sample being selected in Wasit Governorate.

\subsection{Value of the Study}

This study may be of great value since it is hoped to:

1. Show the effect of Focus technique on teaching and learning English as a foreign language.

2. Improve the creative writing skill performance of the fifth grade students at the preparatory schools.

3. Encourage and motivate students to improve their abilities in creative writing skill.

4. Guide Iraqi EFL preparatory school teachers to use better techniques to develop students' performance in creative writing skill. 


\subsection{Procedures}

1. Selecting a sample of fifth preparatory school students, who are randomly divided into two groups: a control group and an experimental group.

2. Constructing a pre-test and a post-test exposed to experts to ensure its validity; and calculating its reliability and item analysis.

3. Administering a pre-test to the experimental and control groups to assess the level of students in learning creative writing skill

4. Teaching creative writing skill to the control group by using the current technique and to the experimental group by using Focus technique.

5. Conducting a final administration of the post-test to the learners of creative writing skill performance

6. Analyzing the collected data to get results using suitable statistical tools; and finally presenting the results to come up with conclusions, recommendations, and suggestions for further studies.

\subsection{Definitions of Basic Terms}

\subsubsection{Focus}

Is the starting point for any serious creativity session, which aims to generate new ideas. The exercise of this strategy requires creative thinking about different attitudes that the individual is supposed to address. [10]

\subsubsection{Creative Writing}

Creative Writing is any writing that goes outside the bounds of normal professional, journalistic, academic, or technical forms of literature, typically identified by an emphasis on narrative craft, character development, and the use of literary tropes or with various traditions of poetry and poetics. Due to the looseness of the definition, it is possible for writing such as feature stories to be considered creative writing, even though they fall under journalism because the content of features is specifically focused on narrative and character development. Both fictional and fictional works fall into this category, including such forms as novels, biographies, short stories, and poems. [11]

\section{Theoretical Background and Previous Studies}

In traditional approaches model, creative writing, especially nonfiction writing, may an inspirational entry point to introduce students to writing. Although there has been limited research on teaching creative writing to students who write in a second/foreign language, those who have worked and researched in the area often recognize the importance of self-expression.

Fearnside argues that writing in a second/foreign language builds critical thinking, teaches culture and provides 'a chance to do something perceived as "fun" while still requiring a lot of work' from students.[12]

Hanauer also agrees Widdowson who pointed out that second/foreign language teaching is often decontextualized, in spite of the best efforts of the communicative approach. [13]

Language learning can become real only when 'it is reconnected up with context of some kind,' yet the context of the classroom is 'entirely different from those [contexts] that gave rise to the language in the first place,' and that the second/foreign language classroom needs a 'pedagogic artifice' for students to learn [13].

Stresses 'meaningful literacy instruction,' where the language learner is considered 'a socially and culturally contextualized individual with a rich, extended history of personal experience.' Holding that the 'living, thinking, experiencing and feeling person' is at the center of language learning, Such instruction takes language learning as part of a process through which the student 'can understand, interpret, feel and express her or his personally meaningful understandings,' and that it involves 'interaction with everything that makes up the experience and understanding of the learner' In other words, the concept of meaningful literacy positions the learner and her/his 'personal experience, history and social contextualization at the center of the learning experience'.[14]

However, meaningful literacy leads to language use that comes from 'the true desire for personal expression,' and as a result, language learning is centered around 'authentic, meaningful, personal expression,' where '[the] real reason for learning a language becomes an issue of extending personal understanding and personal expression'. [15]

In teaching the writing of poetry in English to non-native speakers, [15] has grounded his approach to 'meaningful literacy instruction' on four principles: (i) autobiographical writing which enables students to enact personal experience to understand the self; (ii) emotional writing which encourages the expression of personal feeling on the writer's part and emotional responses on the reader's part; (iii) personal insight which integrates the student's reflection with his/her new appreciation of personal experience; and (iv) authentic public access through which the student's work is shown in the classroom and to people close to the writer. In this context, therefore, language teaching 'enacts a process in which the language learner's memory, experiences, feelings, beliefs, history, and social environment are the context of language use'

\subsection{Focus Strategy}

Focus strategy is one of the strategies of a serious creativity by Edward De Bono; it is the starting point for any serious creativity session, which aims to generate new ideas. The exercise of this strategy requires thinking about different and different attitudes that the individual is supposed to address. [16]

\subsection{The Steps of the Focus Strategy}

1. Declares the specific point of focus for the learninglearning task that students will undertake by way of writing on the blackboard, such as: (rights, justice, 
summer vacation... and others).

2. Students are required to make the focus that they have identified their focus.

3. Instructs students to adjust, or to determine the appropriate learning method for the time, and for the learning-learning task.

4. Adjust the time needed to focus on a task; keep away from dispersion factors

\subsection{The Importance of Focus Technique in Teaching Creative Writing}

Using Focus technique in teaching creative writing is better than any other technique because it enables teachers to teach writing in creatively which is the way people learn their native language.

De Bono [10] mentions five reasons to teach creative thinking with Focus: First, by using Focus in teaching writing, students can generate new ideas. Second have a new realizing, so, focus is regarded as cognitive activities. Third, using focus motivates students and increases the cooperation in the classroom and this creates positive atmosphere. Fourth, learning new alternatives in English Fifth, students get new creation. Focus facilitates the matter because it is amusing and creative and they allow meaningful use of the language in context.

\section{Procedures and Methodology}

The following pages present a detailed description of the procedure that is followed in order to achieve the aim of the study and verify its null hypothesis.

\subsection{The Experimental Design}

The design of this experiment is the kind of pretestposttest control and experimental group design. [17] It presents the selection of two groups randomly. Both groups are submitted to a pre-test and afterward the group work technique (independent variable) is administered to the experimental one only, i.e., the control one was taught by the conventional method. Yet, the groups are submitted to a posttest in order to compare the scores of the pre-test, post-test on the dependent variable (short stories) and determine whether or not there is any statistically significance of difference between both groups. [18]

\subsection{Population and Sample Selection Population}

The study population is the fifth-grade students at the preparatory schools for females in the city center of Wasit Governorate, during the academic year (2018-2019).

\subsubsection{Sample}

Imam Ali preparatory School was chosen to be the sample of this study. The number of students was (75) divided into two sections A and B. one section was selected randomly to represent the experimental (section A) and the control (section B) groups. There were (38) students in group A and (37) students in group B. After excluding the repeaters in each groups, the number of students has become (33) in group A and (32) in group B (see Table 1).

Table 1. TheStudy Sample.

\begin{tabular}{llll}
\hline Group & Section & $\begin{array}{l}\text { Students' number } \\
\text { before exclusion }\end{array}$ & $\begin{array}{l}\text { Students' number } \\
\text { after exclusion }\end{array}$ \\
\hline Experimental & A & 37 & 33 \\
Control & B & 38 & 32 \\
Total & & 75 & 65 \\
\hline
\end{tabular}

\subsubsection{Equivalence of the Sample Subjects}

The two groups were equalized by controlling some variables which may affect the experiment outcomes. These variables are: students' age (measured in months), parents' educational level, and students' scores in English in the first course examination of the same academic year.

The two groups were equivalent in all variables at a time when all external and internal variables that may affect the experimental design had been controlled.

\subsection{Teaching Materials}

Three subjects were selected from units $(5,6,7)$ of the English for Iraq, $5^{\text {th }}$ preparatory student's book and another one from the extra activities of the student's activity book unit (6).

1. Instruction

The instruction of the experiment started on the $19^{\text {th }}$ of February, 2019. It lasted two months and ended on the $30^{\text {th }}$ of March, 2019. In order to control the teacher variable in the experiment, the researcher herself taught both groups the whole material of creative writing. The experimental group was taught by using focus technique in teaching creative writing, whereas the control one was taught the same SSs by using the conventional method (hence forth CM). Typical lesson plans were prepared, and then seen by a jury of fifteen specialists in linguistics and TEFL methodology. The creative writing exercises in student's book and student's activity book were all taught for the two groups.

2. The Performance Test

The performance test according to Davies et al. is a tool made to check what a learner has performed in a specific material. [19]

The researcher has constructed creative writing performance tests which are used as pre-test and post- test for both groups. The pre-test's aim is to compare its scores with those of the post-test and see the effect of using Focus as a new technique on the students' performance in teaching writing.

3. Description of the Pre-test

The creative writing pre-test consists of four different questions. The first one provides students with five comprehension questions which are related to a particular short story, the students' task is to respond to those questions. The second one contains two columns: the first is called definitions column while the second is words column, the students' mission is to read the definitions and match them to the suitable words. The third one has a story of five sentences 
but with incorrect order, so the students have to put them in the correct order. Question four deals with a listening skill, the students listen to a piece of short story, then write (true) or (false) for five statements.

4. The Scoring Scheme

The scoring scheme is a basis in which the researcher thoroughly depends on to interpret the outcomes. A precise scoring scheme must be adopted for reliability and objectivity purposes. [20]

The scoring scheme that was adopted for the four-question tests is as follows: Fifteen marks are allotted for each question, taking into consideration the grammatical errors, spelling errors and punctuation marks. Each question has five items; each item is marked with three scores, so the total mark is sixty.

\section{Validity}

There are many forms of validity, but there are just two forms that are regarded valuable for achievement tests; content and face validity. Both forms have been addressed to evaluate the test and come out with a validated test that yields accurate and truthful outcomes. Face validity means how the test appears to measure what it purports to measure [3]. The test was seen by a jury of fifteen specialists in linguistics and TEFL methodology in order to ensure its face validity. Those experts were asked to decide the face validity of the test and state their suggestions about the suitability of the test and its items to the students' level. The jury members agreed that the test is valid in its face and its items are suitable for the students' level except for some modifications which are taken into consideration.

On the other hand, content validity means how an exam measures in a sufficient and an adequate manner the specified skill or activity it sets out to measure ${ }^{21}$. Since the test was based on the materials of the creative writingh in the students' book and activity book, it has content validity.

6. Pilot Study

The pilot study is defined as an initial step to examine the design and procedures before spending money and time on a particular study. [22]

The pilot study was applied on $13^{\text {th }}$ of February to 90 students randomly chosen from Abu-The preparatory School to represent the pilot study sample.

The pilot study data have been statistically analyzed to determine the discrimination power and the difficulty level of each item.

The results of the pilot study have also shown the practicality of the test and the time required for answering it which ranges between 35 to 40 minutes.

7. Item Facility and Item Discrimination

Item facility refers to the degree to which an item seems to be complicated or facilitated for a particular number of testees. It simply reflects the percentage of learners who answer the item properly. The most appropriate test item will have item facility that ranges from 0.15 to 0.85 . [23]

On the other hand, item discrimination refers to the degree to which an item distinguishes between good and poor testees.
An item has good discrimination power if it collects correct answers from good students and incorrect answers from poor students. It is worth mentioning that high discrimination power will be near to 1.0 , and no discrimination power at all will be zero. [23]

After scoring the test items of the pilot study, the item facility equation was applied for each item. It has been found that all items are appropriate in their difficulty levels because they are between $(0.35)$ and $(0.80)$.

With regard to the discrimination power, the students' scores are arranged from high to low. Then, they are divided into two groups the high, the middle and the lowest scores. The middle scores are eliminated and the other ones are applied to the item discrimination equation. It has been found that all items are of a good power of discrimination because their discrimination levels are more than $40 \%$.

8. Reliability

Reliability pertains to the consistency of test marks, which means that a test would provide similar outcomes, if it was given at a different time) [3].

Kuder-Richardson and Interrater methods were followed to estimate the reliability of the test in the current study. KuderRichardson (KR20) is a tool to measure the internal consistency of a test that its items scored dichotomously [21]. Interrater method refers to the extent to which different testers agree in their evaluations of different subjective ratings of ability [21]. The testees' responses were scored by the researcher himself and another rater. Applying these two methods yielded reliability coefficients of (0.801) and (0.899) successively. This means that the test is suitable for application since Tavakoli [24] (2012: 542) mentions that reliability coefficient of a test would be enough and acceptable if it is not less than (0.50. [24-25]).

9. The Pre-test Final Administration

Both students of the experimental and control groups were pre-tested on the $20^{\text {th }}$ of February 2019. This pre-test aims at comparing the scores of the students' achievement in the pretest with those in the post-test. As a result, the researcher tested and scored the sample of the study. [26]

10. The Post-test

Students of both groups (the experimental and control ones) were post-tested on the $20^{\text {th }}$ of April 2019. The same pre-test procedures were followed in conducting the post-test, namely scoring scheme, validity, pilot study, item difficulty, item discrimination, and reliability. It is worth mentioning that the post- test also was seen by a jury of fifteen specialists in linguistics and TEFL methodology. [27]

\section{The Results}

At the end of the experiment and in order to realize the aim of the study and test its null hypothesis, the data of the pretest and post-test are statistically analyzed. It should be noted that this analysis is undertaken to decide whether there is any significant difference between the two groups in the pre-test and post-test. 


\subsection{Comparison of the Experimental and Control Groups in the Post-test Scores}

The results obtained from the post-test on both groups show that the mean scores of the experimental and control groups in the post-test are (38.00) and (22.75) successively, which means that the experimental group achievement in the SSs is better than that of the control group.

The T-test formula for two independent samples is used to see whether the difference between the two groups is significant or not. The result shows that the computed T- value of the post-test is (5.422), while the tabulated T-value is (2). This indicates that there is a significant difference between the two groups at $(0.05)$ level of significance and under (63) degrees of freedom (see Table 2). This also indicates that the null hypothesis of the study which sets in (1.3) and states that "there is no statistically significant difference between the achievement mean score of the students who are taught short stories through using a group work technique and that of the students who are taught short stories through using the conventional method" is rejected [28].

Table 2. T-test Statistics of the Students' Scores in the Post-test 4.2. Comparison of the Pre-test and Post-test Scores of the Control Group.

\begin{tabular}{|c|c|c|c|c|c|c|c|}
\hline \multirow{2}{*}{ Group } & \multirow{2}{*}{ No } & \multirow{2}{*}{ Mean } & \multirow{2}{*}{ SD } & \multirow{2}{*}{ DF } & \multicolumn{2}{|c|}{ t-value } & \multirow{2}{*}{ Level of significance } \\
\hline & & & & & CTV & TTV & \\
\hline $\begin{array}{l}\text { Experiment al } \\
\text { Control }\end{array}$ & $\begin{array}{l}33 \\
32\end{array}$ & $\begin{array}{l}38.00 \\
22.75\end{array}$ & $\begin{array}{l}13.75 \\
8.11\end{array}$ & 63 & 5.422 & 2 & 0.05 \\
\hline
\end{tabular}

With regard to the control group, the mean scores of the pre-test is (23.125), while that of the post-test is (23.593). The one sample T-test formula is used to find out whether there is any significant difference between the pre-test and post- test scores or not. The result shows that the computed
T- value is (20.712), whereas the tabulated T-value is (2). This means that there is a slight difference between them, i.e. the post-test is a little bit higher than the pre-test (see Table $3)$.

Table 3 T-test Statistics of the Students' Scores in the Pre-test and Post-test for the Control Group.

\begin{tabular}{|c|c|c|c|c|c|c|c|}
\hline \multirow{2}{*}{ Test } & \multirow{2}{*}{ No. } & \multirow{2}{*}{ Mean } & \multirow{2}{*}{ SD } & \multirow{2}{*}{ DF } & \multicolumn{2}{|l|}{ t-value } & \multirow{2}{*}{ Level of Significance } \\
\hline & & & & & CTV & TTV & \\
\hline Pre-test & 32 & 23.125 & 9.061 & \multirow{2}{*}{62} & \multirow{2}{*}{20.712} & \multirow{2}{*}{2} & \multirow{2}{*}{0.05} \\
\hline Post-test & 32 & 23.593 & 9.122 & & & & \\
\hline
\end{tabular}

\subsection{Comparison of the Pre-test and Post-test Scores of the Experimental Group}

Concerning the experimental group, the pre-test and posttest mean scores are found to be (21.515) and (38.000) successively. The one sample T-test formula is exploited again to determine whether or not there is any significance of difference between the pre-test and post-test scores. The calculated T-test is found to be (15.454), whereas the tabulated one is (2). This denotes that the pre-test and posttest are significantly different at (0.05) level of significance and under (63) degrees of freedom. Namely, the post-test of the experimental group is much better than the pre-test (see Table 4)

Table 4. T-test Statistics of the Students' Scores in the Pre-test and Post-test for the Experimental Group.

\begin{tabular}{llllllc}
\hline \multirow{2}{*}{ Test } & No. & Mean & SD & \multirow{2}{*}{ DF } & & \multicolumn{2}{c}{ t-value } \\
\cline { 4 - 7 } CTV & \multirow{2}{*}{ Level of Significance } \\
\hline Pre-test & 33 & 21.515 & 12.949 & 15.454 & 2 \\
Post-test & 33 & 38.000 & 13.756 & 64 & 0.05 \\
\hline
\end{tabular}

\subsection{Discussion of the Results}

Building upon the results of the study, it has been figured out that there is a significant difference between the experimental and the control groups. With regard to the posttest, the mean score of the experimental group is (38.00), whereas that of the control group is (22.75). This signifies that the students' achievement of the experimental group is significantly better than that of the control group.

It has been concluded that the Focus technique which is employed to teach the second intermediate students of the experimental group, is considered more effective, useful, and favorable to teaching creative writing than the conventional one. [29]

\section{Conclusions}

In the light of the empirical proof shown in this work and in relation to the researcher's own observations throughout the experiment, the following conclusions are drawn:

1. Teaching SSs through the use of Focus has a significant effect on developing the general ability of second-year intermediate students.

2. The time allotted for teaching creative writing sections in students' book is not adequate; as a result, creative writing sections are almost neglected by teachers.

3. In terms of psychology, using Focus in teaching creativity writing motivates students and creates an atmosphere of enjoyment and interest that makes them 
breaking the regular routine.

4. The use of Focus provides students with the experience they need for social development.

5. Through Focus, the students have proved to be more vital because they are given sufficient chances to use foreign language themselves without direct control of the teacher.

6. Focus makes low level students involving in the class activities and gives them more chances to get more information and explanation from their group members.

\section{References}

[1] Harper, G. (2014) Creative Writing and Education. Oakland University, Rochester, USA/.

[2] Harper, Graeme (2012), Inside Creative Writing: Interviews with Contemporary Writers, London: Palgrave-Macmillan.

[3] Coombe, Christine. (2010). Assessing English Language Learners. Ann Arbor: The University of Michigan Press.

[4] Mills, S. (2003). Gender and Politeness. England, Cambridge: Cambridge University Press.

[5] Richard, Jack C and Willy A Renandya.(2002). Methodology in Language Teaching: An Anthology of Current Practice. Cambridge University.

[6] Edberg, Hélène (2015). Creative Writing for Critical Thinking Creating a Discoursal Identity Orebro studies in Rhetoric 8, pp. 13-130.

[7] Olson, C. B. (2007). Reading /writing Connection Strategy for Teaching and Learning in the secondary Classroom. New York: Longmab.

[8] Hewings, A., Perscot, L. and Seargent P.(2016). Futures for English Syudies Teaching. New York: NY 10010.

[9] De Bono, Edward (2015). Serious Creativity: How to be creative under pressure and turn ideas into action. $2^{\text {nd }}$, London, United Kingdom: Ebury Publishing.

[10] Kauffman, S. B. \& Kauffman, J. C. (2009). The Psychology of Creative Writing, 2ed, Cambridge: Cambridge University Press.

[11] Bennet, A., C; arke, G., Motion, A., \& Naidoo, B. (2008) Creative Writing Benchmark Statement. www. nawe.co.uk/writing -in-education.

[12] Fearnside, (2003). Teaching creative writing in English in the Chinese context. https://doi.org/10.1111/weng.12136.

[13] Widdowson, G. (1998) Context, Community, and Authentic Language. https://doi. org/10.2307/3588001.

[14] Healey, Stephen, (2009) "The Rise of Creative Writing \& the New Value of Creativity," The Writers Chronicle, Vol. 41, No. $4,30-39$.
[15] Harmer, Jeremy. (2002) The Practice of English Language Teaching 3 ed. United Kingdom: Longman Publishing.

[16] De Bono, Edward (2007). Intelligent information thinking. $1^{\text {st }}$, London, United Kingdom: blackhall Publishing.

[17] Tavakoli, Hossein. (2012). A Dictionary of Research Methodology and Statistics in Applied Linguistics. Tehran: Rahnama Press.

[18] Ali, Dh. B, Dehham S. H.\& Hasan A. A. (2019). The Effect of Using Index Cards Games Technique on Iraqi EFL Intermediate Students' Performance on Writing Skill. V 10. Issue 1. Indian Journal of Public Health Research \& Development.

[19] David P. (1969). Testing English as a Second Language. New York: Holt, Rinehart and Winston, Inc.

[20] Harrocks, John E. and Schonnover, Theima I. (1968). Measurement for Teachers. New York: Charles E. Merril Publishing Company.

[21] Richards J. C. and T. S. Rodgers. (1988). Approaches and Methods in Language Teaching: A Descriptive Analysis. Cambridge: Cambridge University Press.

[22] Eysenck, Michael. W. and Flanagan, Cara. (2000). Psychology for Advanced Level. New York: Psychology Press Ltd.

[23] Brown, H. Douglas. (2010). Language Assessment Principles and Classroom Practices. Second Edition. US: Pearson.

[24] Dehham, S. H.(2018). The Role of Contextualized Testing Technique in Enhancing EFL Intermediate Students' Capacity in Acquiring English Vocabulary. Vol. 1, No. 6, pp. 128-136. Sumerianz Journal of Education, Linguistics and Literature.

[25] Abbas, I. H., Sabeeha, H. D. Nadia, A. (2018). The psychological effects of clickers technology on english language students. 9 (10): 740. Indian Journal of Public Health Research \& Development.

[26] Rahoomi, R. K., Sabeeha, H., Dehham, M., A.(2019). The Impact of Reading Strategy Knowledge and Science Knowledge on Developing Reading Skills of School Students. V. 10. Indian Journal of Public Health Research \& Development.

[27] Hammad, A. A., Sabeeha, H. Dehham, Nadia, A.(2018). The Impact of Using Tablets on Developing Listening Skill \& perception as a Brain Process of EFL. V9 No. 12. Indian Journal of Public Health Research \& Development.

[28] Hussein, Z, M., Sabeeha, H. Dehham \& A. A. (2019). The Impact of Using Chunking Technique on Developing Reading Skill and Perception of Intermediate. V 9. No. 6. Indian Journal of Public Health Research \& Development.

[29] Kareem, H. H., Sabeeha, H. Dehham \& M. A. (2019). The Impact of Teaching the Creative writing by FOCUS Strategy to Develop. V. 10. No. 6. Indian Journal of Public Health Research \& Development. 